The Treatment vs. the Abortion of Typhoid Fever.

Youngstown, Ohio, Dec. 24, 1894.

To the Editor:-During the past year you have published four papers on typhoid fever, which I had read before the Mississippi Valley Medical, the American Medical and the Mahoning County Medical Societies. Those papers were all written for one object,-to prove that typhoid fever can be aborted-a difficult enough task surely; without wasting much time in giving details of a treatment which I did not suppose many would care to try until very conclusive evidence of its efficacy had been presented, but although, some physicians have secured most brilliant results from the treatment by relying on these published directions as their only guide, I fully recognize their inadequacy and have always intended to write a treatise on the abortive treatment of typhoid fever, as soon as there seemed to be a demand for it.

Since the publication of my first paper in February last, I have received many letters asking for exact details of my method of aborting typhoid fever, but I do not find the name of Dr. W.S. Caldwell of Freeport, Ill. He must therefore have obtained his whole knowledge of this important sub ject from one or more of these incomplete papers written for an entirely different purpose. Yet he published a letter in the Jourval of the 15th inst., in which he confesses his inability to succeed with a treatment of which he must necessarily know so little. Immediately on receipt of the JouRnal, containing his criticism, I wrote him the following polite letter:

Youngstown, Ohio, Dec. 15, 1894.

My Dear Dr. Caldwell:-Presuming that the object of your letter in the current issue of the Journal of THE American Medical Association is to "seek for the truth," and believing that if put in possession of all the data at your disposal, I could not only show you why you failed to secure the results which my charts show are possible, but how you may obtain even better results than I have had, because my work has been done under difticulties and 1 have made many mistakes which you could avoid.

Will you therefore give me the necessary information by answering the inclosed list of questions:

1. How many cases of typhoid fever have you treated by my method?

2. On what day of the disease did you begin the treatment of each case?

3. What was each patient's condition when the treatment was begun?

4. What was the exact formula used in each case?

5 . What was the size of doses given?

6. How often were they given during the first six days?

7. What other medicines were given besides those advised by me?

8 . What was the daily morning and evening temperature?

9 . Give the pulse record.

10. How many times did the bowels move each day?

11. How soon after beginning treatment did the tympanitis disappear?

And add any further information that you may possess about them. Will you also send me samples of the remedies you used, or if this is not possible give me the name of the druggist who prepared them for you, so that be may send me sample on order?

Hoping to hear from you at once, I beg to remain, my dear sir,

$$
\text { Most respectfully yours, }
$$

JoHN Eliot Woodbridat.

P. S.-Should you have other cases of typhoid fever and will telegraph me, I will go to Freeport free of cost to your patient or yourself, and show you how to shorten the course of the disease to less than two weeks and how to save the life of every patient.

This letter he prob :bly does not consider worthy of his attention, as more than a week has elapsed and I have received no answer. His published letter is therefore the only measure I have by which to judge of his ability to treat a case of the disease which he truly designates "terrible."
First, he says I have published . . . . "in several medical journals." . . . . This is not true. I have never published a paper on typhoid fever in any journal, magazine or paper, except the Journal of tue Auerican Medical Association. One paper was published in the Transactions of the Ohio State Medical Society.

a "paper" . . . . So he probably has seen but one of my five published papers on the subject, and he does not say which one.

He next errs by calling a paper or series of papers, written to prove that typhoid fever can be aborted. . . . "paper on the treatment of typhoid fever." Notwithstanding the fact that less than two and one-half of the sixty pages, refer to treatment. He says: "The first part of his prescription" (by which he evidently means-first prescription)-"containing" "guaiacol." Is this only an inaceuracy, or does Dr. Caldwell not know the difference between "guaiacol" an acrid, poisonous, oily liquid and guaiacol carb., a white, crystalline non-poisonous salt?

It would be unreasonable to suppose that Dr. Caldwell would write with less care or less accurately for the thousands of readers of the Jovrnal than he would for his druggist. Therefore judging his prescriptions by his published criticism we are justified in giving expression to some surprise that "his vigorous young woman" was in condition to have a temperature of 105 degrees F. after "two weels trial" without taking into consideration the fact that she was subjected to at least three different methods of treatment, viz., the Brand or bath, the Woodbridge, and the compromise or sponge treatment.

Without taking the trouble to criticize the remainder of this letter, it seems clear that if others have tried $m y$ abortive treatment of typhoid fever with no better preparation and as carelessly as the Doctor's letter would lead us to suppose he conducted his experiment, then we shall probably hear of other failures as dismal. We shall undoubtedly hear, too, of some successes, and one brilliant success should outweigh an hundred failures in estimating the value of the treatment. The failures may be due to inert or impure drugs, to carelessness or want of skill in compounding them, to their improper administration or even to the administration of other remedies interfering with their action. Thus the physician who prescribes, the nurse who administers, the druggist who dispenses, or even the pharmacist who manufactures the remedies, one or all of them may contribute to the failure, making that but at best a negative evidence, while a single well established success puts the stamp of value on the treatment. The gun that speeds the bullet true to the mark in one hand, if equaliy well charged and truly held, will do so in every hand, but if the powder be poor, the bullet untrue, or the hand that holds the gun unsteady, no matter how accurate the weapon may be. the bullet may be expected to fly wide of the mark.

Respectfully yours,

John Eliot Woodiridge, M.D.

\section{Treatment of Typhoid Fever.}

Columbiana, Ohio, Dec. 25, 1894.

To the Editor:-In response to the physician who has been using Dr. Woodbridge's treatment for typhoid fever and has not met with the success he had hoped for and that Dr. Woodbridge had assured him he would meet with; and to all who would try it, I desire to say that I have been carefully testing it for the past three months, and so far it has proved very successful in my hands. In that time I have had an unusual number of cases of typhoid fever. Not being satisfied with the old method of treatment, I was induced to try the plan proposed by Dr. Woodbridge. Some of my cases presented unusually severe symptoms, temper- 
ature ranging as high as 105.5. While I was not able to abort it entirely in all of my cases, yet the temperature was materially reduced in a very short time, the fever ran a very mild course and my patients were soon in a convalescent stage.

I find this treatment must be employed early. In one or two cases I used other measures first; finding they did not accomplish the end desired, I then adopted the Woodbridge method after a delay of a day or so. In these cases my results were not so good as when I used his measures first. Perhaps the physician who says he practices very conservatively, failed to use the measures early enough to abort the disease, and thus became discouraged with the remedy. If this gentleman, and others also, will give the method a fair trial, using the treatment early and calling Dr. Woodbridge in consultation in the severer cases, allowing him to explain more fully his plan of treatment, I think the results will be more satisfactory.

Yours fraternally,

C. R. Justice, M.D.

Merced, Cal., Dec. 27, 1894.

To the Editor:-Replying to Dr. Caldwell, will say I have tested the antiseptie treatment of Dr. Woodbridge sufficiently to convince me of its great value. I have been unable, so far, to carry out this treatment exclusively from beginning to end of case, for various reasons, but the results obtained in the way I used it, convince me of its superiority. Then it appeals to the reason; it not only destroys the bacilli but carries them off, and by giving large quantities of water we have an (almost) antiseptic irrigation of the tniestines.

W. N. Sherman, M.D.

The Practical Importance of Well Established Facts in Therapeutics.

To the Editor:-Dr.N.S. Davis puts the questions : If alcohol when taken into the living body directly diminishes nerve sensibility, muscular force, and so alters the constituents of the blood as to retard both the internal distribution of oxygen and natural tissue metabolism in direct proportion to the quantity to be taken (the established fact according to Dr. Davis), why do we continue to speak and write concerning it, or to use it, as a stimulant, heart tonic or restorative agent? The answer seems to be that experience proves that we are right in spite of the supposed established facts.

Let me briefly illustrate: In the year $1870 \mathrm{I}$ started to walk from Courmayeur to Chamounix via the Col du Geant, a climb of 10,000 feet and a march of some six or seven hours over the Mer de Glace. I arrived at the summit of Col between 9 and 10 o'clock A.M., and after resting one hour for breakfast, commenced the descent. At this hour the heat was intense, and the motion of walking on the glacier was as irregular and uncertain as on board a ship. I was seized with mal de montaigne, vomiting, diarrhea and nervous prostration exactly similar to similar experiences at sea, and I lay down for an hour and slept, but no sooner did I begin to walk than the vomiting returned. My guides and porter made a chaise $a$ porteur of their staves and alpenstocks. They essayed to carry me, but the motion of their movements was even worse than that of walking and the attempt was given up. With the prospect of being benighted on the ice I then sent on two men to Montainvert with instructions to return as quickly as possible with wraps, fuel, restoratives and other requirements for passing the night in safety. In the meantime I struggled on for a few yards at a time. until at last even a few steps brought on such prostration that I was compelled to stop. My condition became alarming, my face was deathly, I was pulseless, my hands and feet cold and $I$ was quite unable to rise ; and my friends covered me up in shawls, chafed my hands and did their best to maintain my circulation. We were waiting most anxiously for the return of my men with the necessary restoratives, when we were accosted by an Irish gentleman on his way to spend the night upon the glacier with the object of climbing one of the neighboring peaks to see the sun rise. He saw and diagnosed my case. He took out his flask of brandy and in the course of fifteen minutes gave me fully half a pint without a drop of water. Within another ten minutes I got up and shook myself and declared my ability to walk. I boasted of having on a pair of brandy boots. I walked forward without a trace of nausea, crossed the "Mauvais pass" without assistance or mistake, and arrived at the Hotel Montainvert after three hours hard walking, and after a long sleep awoke to eat the heartiest breakfast of my life. It is safe to say that the sensibility of $m y$ nerves was not reduced, that the distribution of oxygen was not retarded, that the natural tissue metabolism was not interfered with. On the contrary, my nerves were stimulated, my heart action was excited and my whole body and muscular system was raised to a condition wonderfully like health.

Let me give one more personal experience: Just eleven years ago I had been greatly overworked and had lost much sleep. I was in close attendance upon a patient who died from pneumonia of a most malignant type. I paid him a long visit a few hours before his death and although boasting to a friend of my perfect health I remarked on getting into bed that I felt a curious sensation in my right loin as though I had suffered from a blow. I slept well but next morning the pain returned. Then cough, hemoptysis, rapid pulse. Temperature 104 degrees and in twenty-four hours all the symptoms of double pneumonia were manifest. At the age of 62 , with an intermittent pulse the prospect was not flattering. On consultation, alcohol was the remedy prescribed. I took half an ounce of brandy or whisky every two hours. The pulse became regular and the symptoms slowly declined. I took the dose religiously for nine days and $m y$ recovery was perfect. I am to-day in my seventy-fourth year. Only a few weeks ago I climbed 3,200 feet in three hours and a quarter, without the least distress, and the day afterward walked for at least seven hours. I do not remember the time when I have not been accustomed to drink wine with my meals. For over fifty years I have drank wine every day, and I may say truly in the last forty years I have not willingly drank forty glasses of cold water to allay my thirst. After such personal experiences, (and indeed I can relate even more startling results in the case of patients) I may surely be pardoned in doubting the apparent facts which Dr. Davis regards as well established.

Yours very obediently,

J. H. STallarD, M.B. Lond., M.R.C.P., M.R.C.S., and late Physician to the San Francisco Polyclinic.

\section{PUBLIC HEALTH.}

Low Death Rate.-Computed on the figures of the school census of April, 1894-which fixed the population at 1,567,727, or 32,273 less than the population of 1893-the death rate of Chicago last year was 15.1 per 1,000 . The Health Commissioner, Dr. Reynolds, reports 23,701 deaths from all causes, as against 27,083 during the previous year.

Glanders in Havana.-El Progreso Medico states that, while glanders has been known to exist in Havana for years, the unusual number of cases in 1894 ought to attract the attention of the health authorities. The remedy is well known to science, but the authorities either don't know it or won't apply it. It is not grooms alone who contract the disease; 